\title{
Membrane Channel Forming Polypeptides. 270-MHz Hydrogen-1 Nuclear Magnetic Resonance Studies on the Conformation of the 11-21 Fragment of Suzukacillin ${ }^{\dagger}$
}

\author{
M. Iqbal and P. Balaram*
}

ABSTRACT: $270-\mathrm{MHz}{ }^{~} \mathrm{H}$ NMR studies on the synthetic suzukacillin fragments Boc-Leu-Aib-Gly-Leu-Aib-OMe (13-17), Boc-Gln-Aib-Leu-Aib-Gly-Leu-Aib-OBz (11-17), Boc-LeuAib-Gly-Leu-Aib-Pro-Val-Aib-Aib-OMe (13-21), and BocGln-Aib-Leu-Aib-Gly-Leu-Aib-Pro-Val-Aib-Aib-OMe (11-21) have been carried out in $\mathrm{CDCl}_{3}$ and $\left(\mathrm{CD}_{3}\right)_{2} \mathrm{SO}$. The intramolecularly hydrogen-bonded amide hydrogens in these peptides have been identified by using solvent titration experiments and temperature coefficients of $\mathrm{NH}$ chemical shifts

\footnotetext{
$\mathrm{T}$ he 24-residue, a-aminoisobutyric acid (Aib) ${ }^{1}$ containing polypeptide suzukacillin modifies the permeability properties of lipid bilayers by the formation of transmembrane channels (Jung et al., 1976; Boheim et al., 1976). The presence of a large number of Aib residues in the sequence (Figure 1) greatly restricts conformationalfreedom of the peptide backbone. The tendency of Aib-containing sequences to adopt $3_{10}$ helical conformations has been clearly established in studies of alamethicin fragments (Nagaraj et al., 1979; Rao et al., 1979, 1980; Nagaraj \& Balaram, 1981a) and model peptides (Prasad et al., 1979, 1980; Shamala et al., 1978; Venkatachalapathi et al., 1981; Venkatachalapathi \& Balaram, 1981). As part of a continuing program to elucidate the conformational characteristics of Aib-containing membrane active peptides,
}

\footnotetext{
† From the Molecular Biophysics Unit, Indian Institute of Science, Bangalore 560 012, India. Received January 27,1981. This work has been supported by a grant from the Department of Science and Technology, Government of India. M.I. is the recipient of a Teacher-Fellowship of the University Grants Commission. P.B.is the recipient of a UGC Career Award.
}

in $\left(\mathrm{CD}_{3}\right)_{2} \mathrm{SO}$. The peptides are shown to favor conformations stabilized by intramolecular $4 \rightarrow 1$ hydrogen bonds. The 11-21 fragment adopts a highly folded, largely $3_{10}$ helical conformation stabilized by seven intramolecularhydrogen bonds. An eighth $\mathrm{NH}$ group [Gly(5)] appears to be involved in a weaker interaction. Evidence for the possible participation of the Gln side-chain carboxamide group in hydrogen bonding to the peptide backbone is also presented.

we have undertaken a detailed study of suzukacillin. An earlier report described the $3_{10}$ helical folding of the amino-terminal decapeptide (1-10) segment (Iqbal \& Balaram, 1981). In the present paper, we summarize the results of $270-\mathrm{MHz}^{1} \mathrm{H}$ NMR studies on the 11-21 suzukacillin fragment and compare the results obtained with studies on smaller fragments. It is clearly shown that the 11-21 fragment is highly folded in solution, and the NMR evidence strongly favors a conformation in which seven $\mathrm{NH}$ groups participate in intramolecular hydrogen bonding.

Materials and Methods

The peptides Boc-Leu-Aib-Gly-Leu-Aib-OMe (1), BocGln-Aib-Leu-Aib-Gly-Leu-Aib-OB\&2), Boc-Leu-Aib-Gly. Leu-Aib-Pro-Val-Aib-Aib-OMe (3), and Boc-Gln-Aib-LeuAib-Gly-Leu-Aib-Pro-Val-Aib-Aib-OMe(4) were synthesized

\footnotetext{
${ }^{1}$ Abbreviations used: Aib, a-aminoisobutyricacid; Boc, tert-butyloxycarbonyl; $\mathrm{OMe}$, methyl ester; $\mathrm{OBz}$, benzyl ester; TLC, thin-layer chromatography.
} 


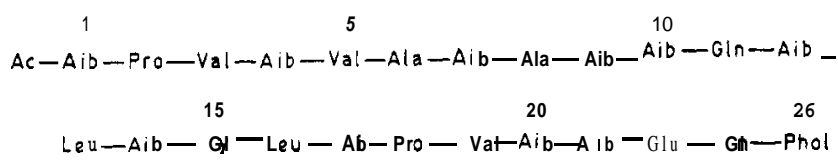

FIGURE 1: Sequence of suzukacillin.

by solution phase procedures, as described for alamethicin (Nagaraj \& Balaram, 1981b). All peptides were homogeneous by TLC on silica gel and were characterized by $270-\mathrm{MHz}^{1} \mathrm{H}$ NMR. Detailed synthetic procedures will be described elsewhere.

${ }^{1} \mathrm{H}$ NMR spectra were recorded on a Bruker WH-270 FT NMR spectrometer at the Bangalore NMR Facility. The ${ }^{2} \mathrm{H}$ resonance of $\mathrm{CDCl}_{3}$ and $\left(\mathrm{CD}_{3}\right)_{2} \mathrm{SO}$ were used for internal field frequency locking. Spectra were recorded at concentrations of $10 \mathrm{mg} / \mathrm{mL}$, using a sweep width of $3012 \mathrm{~Hz}$ with $8 \mathrm{~K}$ real data points, yielding a digital resolution of $0.367 \mathrm{~Hz}$ /point. Solvent titration experiments were carried out by adding a peptide solution in $\left(\mathrm{CD}_{3}\right)_{2} \mathrm{SO}$ to a peptide solution in $\mathrm{CDCl} \mathrm{C}_{3}$. Concentrations of $10 \mathrm{mg} / \mathrm{mL}$ were maintained throughout. Variable-temperature measurements were made in $\left(\mathrm{CD}_{3}\right)_{2} \mathrm{SO}$ over the range $20-80^{\circ} \mathrm{C}$. The probe temperature was regulated with a B-ST 100/700 temperature controller.

\section{Results}

Assignments of NH Resonances. The low-field NH region of the $270-\mathrm{MHz}{ }^{1} \mathrm{H}$ NMR spectra of the suzukacillin fragments 1 (13-17), $2(11-17), 3(13-21)$, and 4 (11-21) are shown in Figures 2-4. In the pentapeptide 1, the two Leu $\mathrm{NH}$ groups appear as doublets. The high-field doublet in $\mathrm{CDCl}_{3}$ is assigned to the urethane $\mathrm{NH}$ (Nagaraj et al., 1979; Nagaraj \& Balaram, 1981a). The corresponding assignment in $\left(\mathrm{CD}_{3}\right)_{2} \mathrm{SO}$ is based on spectra in $\mathrm{CDCl}_{3}-\left(\mathrm{CD}_{3}\right)_{2} \mathrm{SO}$ mixtures. The assignment of the Gly $\mathrm{NH}$ to the triplet resonance is unequivocal. The Aib(2) and $\mathrm{Aib}(5) \mathrm{NH}$ singlets are assigned on the basis of conformational arguments, outlined later. In the heptapeptide 2, the $\mathrm{Gln}(1) \mathrm{NH}$ is readily assigned to the 67.256 doublet in $\mathrm{CDCl}_{3}$ on the basis of its broadening at high temperatures. An unambiguous distinction between the Leu(3) and Leu(6) NH groups is not possible. Similarly the Aib NH resonances cannot be assigned to specific residues.
In the nonapeptide $\mathbf{3}$, the Leu and Val $\mathrm{NH}$ doublets were distinguished by using spin decoupling experiments. An unambiguous assignment of the $\mathrm{Val} \mathrm{C}^{\beta} \mathrm{H}$ resonance at 62.33 is possible by comparing resonances in model peptides containing Leu and Val residues. This permits assignment of the $\mathrm{Val} \mathrm{C}^{\alpha} \mathrm{H}$ resonance and consequently the $\mathrm{NH}$ group. The Leu(1) and Leu(4) NH groups are assigned as in the case of 1. Once again a unique assignment of the Aib $\mathrm{NH}$ resonances to specific residues is not possible. In the undecapeptide 4 , the Leu and Val NH groups were assigned by comparison with the nonapeptide 3. An unambiguous assignment of the individual Leu and Aib NH resonances is not possible. In the case of peptides 2 and 4, the side-chain carboxamide protons of Gln could be readily assigned in $\left(\mathrm{CD}_{3}\right)_{2} \mathrm{SO}$ by their characteristic broadening at higher temperatures. The chemical shifts of the $\mathrm{NH}$ groups in the peptides are summarized in Table I.

Determination of Hydrogen-Bonded NH Groups. The two criteria used for delineation of intramolecularly hydrogenbonded $\mathrm{NH}$ groups were (i) temperature dependence of $\mathbf{N H}$ chemical shifts in a hydrogen-bonding solvent like $\left(\mathrm{CD}_{3}\right)_{2} \mathrm{SO}$ (Kopple et al., 1969) and (ii) sensitivity of NH chemical shifts to solvent composition in the $\mathrm{CDCl}_{3}-\left(\mathrm{CD}_{3}\right)_{2} \mathrm{SO}$ system (Pitner \& Urry, 1972).

The results of variable temperature and solvent titration experiments for peptides $\mathbf{1 , 2}, \mathbf{3}$, and $\mathbf{4}$ are summarized in Figures 5-8. In 1, the Leu(1) NH and one Aib NH [assigned tentatively to $\mathrm{Aib}(2)]$ are clearly solvent exposed, as shown by their high-temperature coefficient $(\mathrm{d} \delta / \mathrm{d} T)$ values of -7 $\times 10^{-3} \mathrm{ppm} /{ }^{\circ} \mathrm{C}$. These two groups also show a steep dependence of chemical shifts on solvent composition (Figure 5). The Gly NH and a second Aib NH group also exhibit relatively high $\mathrm{d} \delta / \mathrm{d} T$ values $\left(4.4 \times 10^{-3}\right.$ and $\left.3.4 \times 10^{-3} \mathrm{ppm} /{ }^{\circ} \mathrm{C}\right)$, characteristic of partially solvent-exposed protons. Only the Leu(4) NH group shows a low $\mathrm{d} \delta / \mathrm{d} T$ value $\left(1.9 \times 10^{-3}\right.$ $\mathrm{ppm} /{ }^{\circ} \mathrm{C}$ ) and a marked insensitivity to solvent, suggesting its involvement in an intramolecular hydrogen bond.

In the heptapeptide 2, both Leu(3) and Leu(5) N H groups show very low $\mathrm{d} \delta / \mathrm{d} T$ values and solvent shifts. One Aib NH group also exhibits characteristics of an intramolecular hydrogen-bonded group. In addition, the Gly N H and one Aib

Bac-GIn-Aib-LeU-Aib-GIV-LeU-Aib-OBz
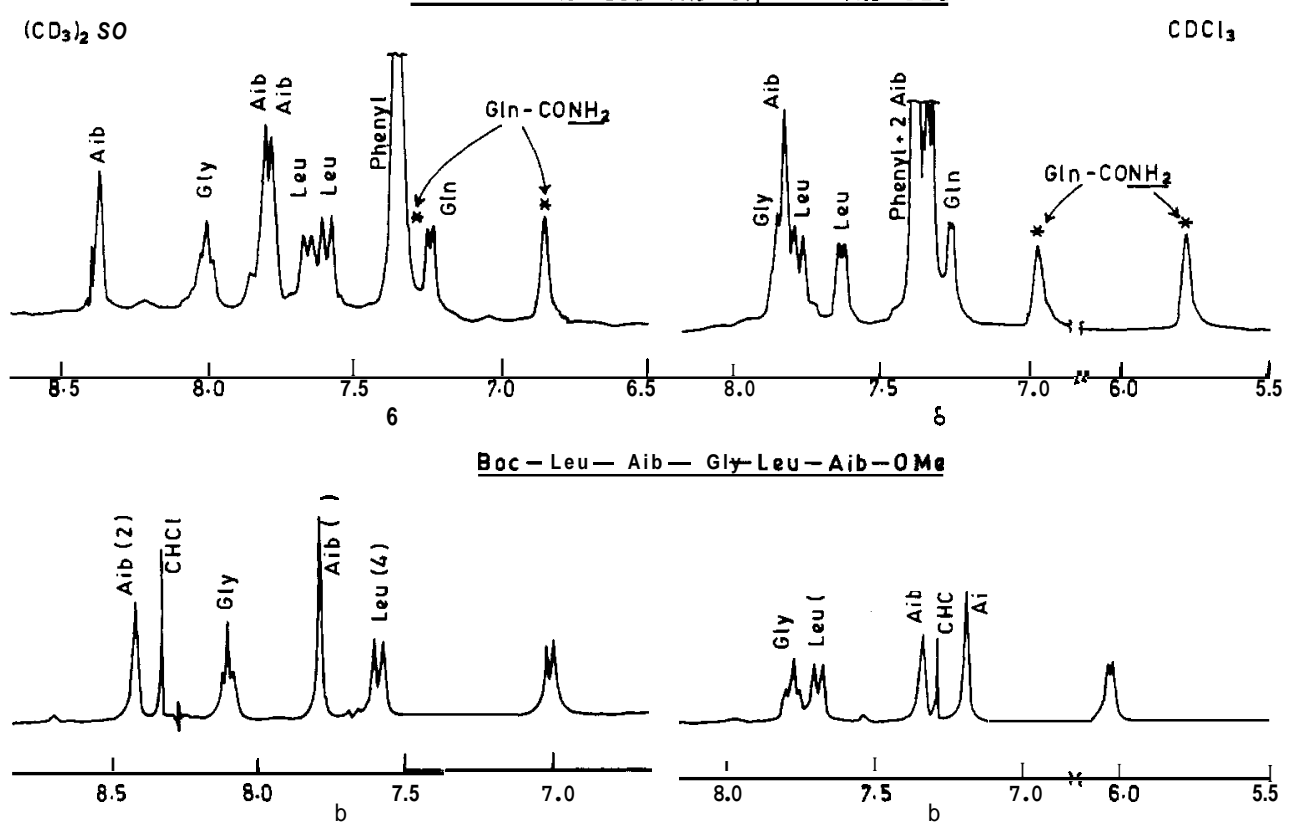

FIGURE 2: 270-MHz ${ }^{1} \mathrm{H}$ NMR spectra of peptides Boc-Leu-Aib-Gly-Leu-Aib-OMe (1) and Boc-Gln-Aib-Leu-Aib-Gly-Leu-Aib-OBz (2) in $\mathrm{CDCl}_{3}$ and $\left(\mathrm{CD}_{3}\right)_{2} \mathrm{SO}$. Only the $\mathrm{NH}$ resonances are shown. 


\begin{tabular}{|c|c|c|c|c|c|c|c|c|c|c|}
\hline peptide & Gln & Aib & Leu & Aib & $\overline{\text { Gly }}$ & Leu & Aib & $\mathrm{Val}$ & Aib & Aib \\
\hline \multirow[t]{2}{*}{$\begin{array}{l}\text { Boc-Leu-Aib-Gly. } \\
\text { Leu-Aib-OMe (1) }\end{array}$} & & & $\begin{array}{r}6.038 \\
(4.1)\end{array}$ & 7.192 & 7.779 & $\begin{array}{l}7.695 \\
(7.7)\end{array}$ & 7.338 & & & \\
\hline & & & $\begin{array}{c}6.990 \\
(6.9)\end{array}$ & 8.402 & 8.084 & $\begin{array}{r}7.580 \\
(8.8)\end{array}$ & 1.781 & & & \\
\hline \multirow{2}{*}{$\begin{array}{l}\text { Boc-Gln-Aib-Leu- } \\
\text { Aib-Gly-Leu-Aib- } \\
\text { OBz (2) }\end{array}$} & $\begin{array}{c}7.256 \\
(1.9)\end{array}$ & 7.804 & $\begin{array}{c}7.605^{b} \\
(5.1)\end{array}$ & $7.278^{b}$ & 7.804 & $\begin{array}{c}1.763^{b} \\
(8.0)\end{array}$ & $7.368^{b}$ & & & \\
\hline & $\begin{array}{c}7.247 \\
(5.1)\end{array}$ & 8.388 & $\begin{array}{c}7.658^{b} \\
(7.8)\end{array}$ & $7.786^{b}$ & 8.029 & $\begin{array}{r}7.590^{b} \\
(8.4)\end{array}$ & $7.786^{b}$ & & & \\
\hline \multirow{2}{*}{$\begin{array}{l}\text { Boc-Leu-Aib-Gly- } \\
\text { Leu-Aib-Pro-Val- } \\
\text { Aib-Aib-OMe (3) }\end{array}$} & & & $\begin{array}{c}6.186 \\
(4.0)\end{array}$ & 7.451 & 7.963 & $\begin{array}{l}1.742 \\
(7.4)\end{array}$ & $7.274^{b}$ & $\begin{array}{c}7.711 \\
(8.8)\end{array}$ & $7.661^{b}$ & $7.109^{b}$ \\
\hline & & & $\begin{array}{c}6.991 \\
(7.0)\end{array}$ & 8.630 & 8.329 & $\begin{array}{l}7.605 \\
(7.4)\end{array}$ & $7.394^{b}$ & $\begin{array}{c}1.693 \\
(9.2)\end{array}$ & $7.856^{b}$ & $7.093^{b}$ \\
\hline $\begin{array}{l}\text { Boc-Gln-Aib-Leu- } \\
\text { Aib-Gly-Leu-Aib- }\end{array}$ & $\begin{array}{r}7.345 \\
(2.5)\end{array}$ & 1.269 & $\begin{array}{c}7.750^{b} \\
(7.0)\end{array}$ & $7.839^{b}$ & 7.860 & $\begin{array}{r}7.617^{b} \\
(5.1)\end{array}$ & $7.116^{b}$ & $\begin{array}{c}7.122 \\
(8.1)\end{array}$ & $7.707^{b}$ & $7.100^{b}$ \\
\hline $\begin{array}{l}\text { Pro-Val-Aib-Aib- } \\
\text { OMe (4) }\end{array}$ & $\begin{array}{l}7.286 \\
(4.4)\end{array}$ & 8.411 & $\begin{array}{r}7.738^{b} \\
(8.8)\end{array}$ & $7.832^{b}$ & 8.213 & $\begin{array}{r}7.593^{b} \\
(7.3)\end{array}$ & $7.378^{b}$ & $\begin{array}{c}7.682 \\
(8.0)\end{array}$ & $7.832^{b}$ & $7.069^{b}$ \\
\hline
\end{tabular}

${ }^{a}$ Values in parentheses are the $J_{\mathrm{HNC} \alpha \mathrm{H}}$ values in $\mathrm{Hz} .{ }^{b}$ Assignments are arbitrary as discussed in the text. ${ }^{c}$ The first row of $\delta$ values are in $\mathrm{CDCl}_{3}$, while the second row are $\left(\mathrm{CD}_{3}\right)_{2} \mathrm{SO}$ values for each peptide.
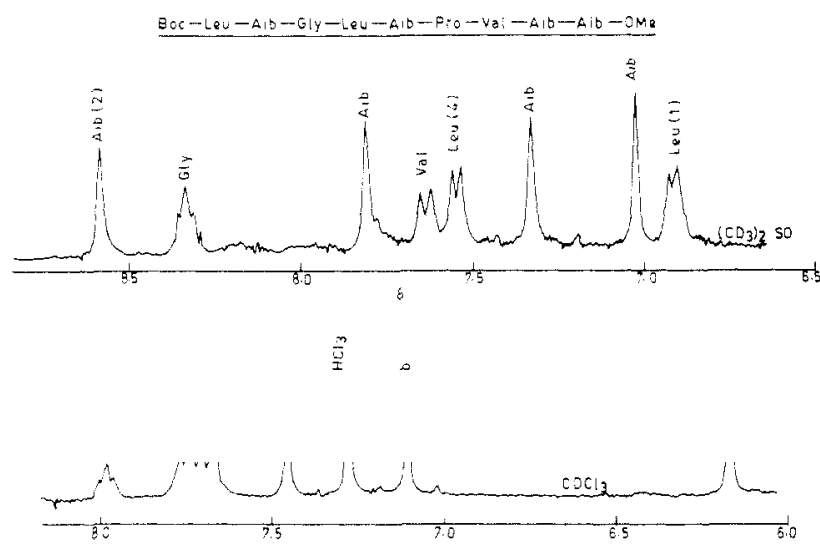

FIGURE 3: NH resonances in Boc-Leu-Aib-Gly-Leu-Aib-Pro-ValAib-Aib-OMe (3) in $\mathrm{CDCl}_{3}$ and $\left(\mathrm{CD}_{3}\right)_{2} \mathrm{SO}$.

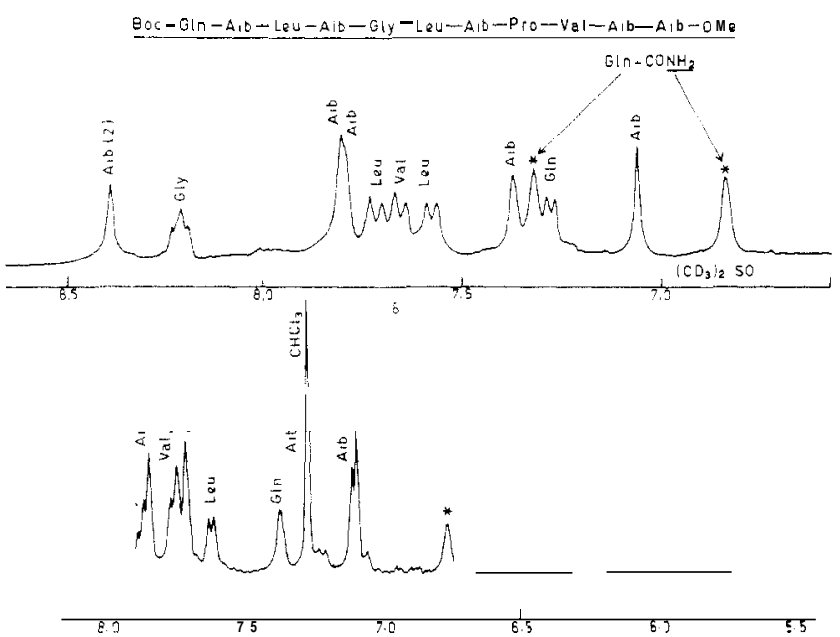

FIGURE 4: NH resonances in Boc-Gln-Aib-Leu-Aib-Gly-Leu-AibPro-Val-Aib-Aib-OMe(4) in $\mathrm{CDCl}_{3}$ and $\left(\mathrm{CD}_{3}\right)_{2} \mathrm{SO}$.

NH also yield moderately low $\mathrm{d} \delta / \mathrm{d} T$ values. The $\mathrm{Gln}(1) \mathbf{N H}$ has a high $\mathrm{d} \delta / \mathrm{d} T$ value in $\left(\mathrm{CD}_{3}\right)_{2} \mathrm{SO}\left(6.9 \times 10^{-3} \mathrm{ppm} /{ }^{\circ} \mathrm{C}\right)$ but exhibits very little solvent dependence of chemical shift. In fact, in both peptides 2 and 4, the $G \ln (1) \mathbf{H N}$ appears at very low field in $\mathrm{CDCl}_{3}$, suggesting its possible participation in a side-chain-backbone hydrogen bond (see Discussion). Another interesting feature of the solvent titration curve in Figure 6 is that the low-field Aib NH is insensitive to addition of $\left(\mathrm{CD}_{3}\right)_{2} \mathrm{SO}$, up to a concentration of $10 \%$, but moves rapidly
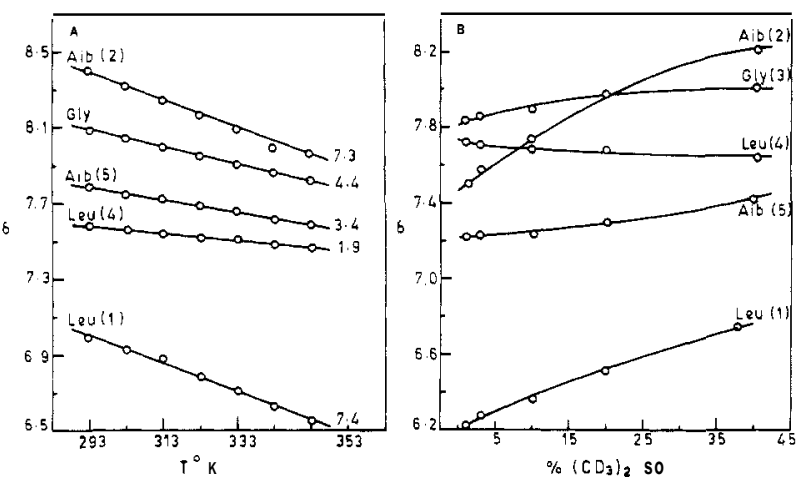

FIGURE 5: (A) Temperature dependence of $\mathbf{N H}$ chemical shifts in peptide 1 in $\left(\mathrm{CD}_{3}\right)_{2} \mathrm{SO} \mathrm{d} \delta / \mathrm{d} T$ values $\left(\times 10^{3} \mathrm{ppm} /{ }^{\circ} \mathrm{C}\right)$ are indicated. (B) Dependence of NH chemical shifts on solvent composition in $\mathbf{1}$.
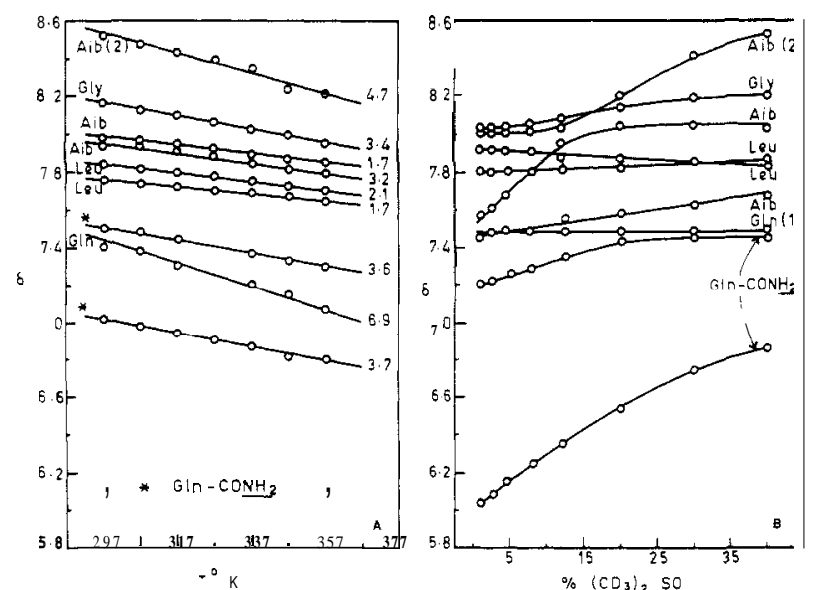

FIGURE 6: (A) Temperature dependence of $\mathrm{NH}$ chemical shifts in peptide 2 in $\left(\mathrm{CD}_{3}\right)_{2} \mathrm{SO} \mathrm{d} \delta / \mathrm{d} T$ values $\left(\times 10^{3} \mathrm{ppm} /{ }^{\circ} \mathrm{C}\right)$ are indicated. (B) Dependence of $\mathbf{N H}$ chemical shifts on solvent composition in 2.

downfield at higher concentrations. This suggests a possible conformational transition at higher $\left(\mathrm{CD}_{3}\right)_{2} \mathrm{SO}$ concentrations.

In the nonapeptide 3, the Leu(1) $\mathbf{N H}$ and one Aib $\mathbf{N H}$ are clearly solvent exposed, as shown by their high $\mathrm{d} \delta / \mathrm{d} T$ values $\left(>7 \times 10^{-3} \mathrm{ppm} /{ }^{\circ} \mathrm{C}\right)$. Of the other $\mathbf{N H}$ groups, only the Gly NH shows a moderately high $\mathrm{d} \delta / \mathrm{d} T$ value. However, the solvent titration curve for this NH group does not show a simple trend, characteristic of an exposed proton (Figure 7). Once again, a single Aib NH group shows a discontinuity in the solvent titration curve, suggestive of a solvent-dependent conformational change. 

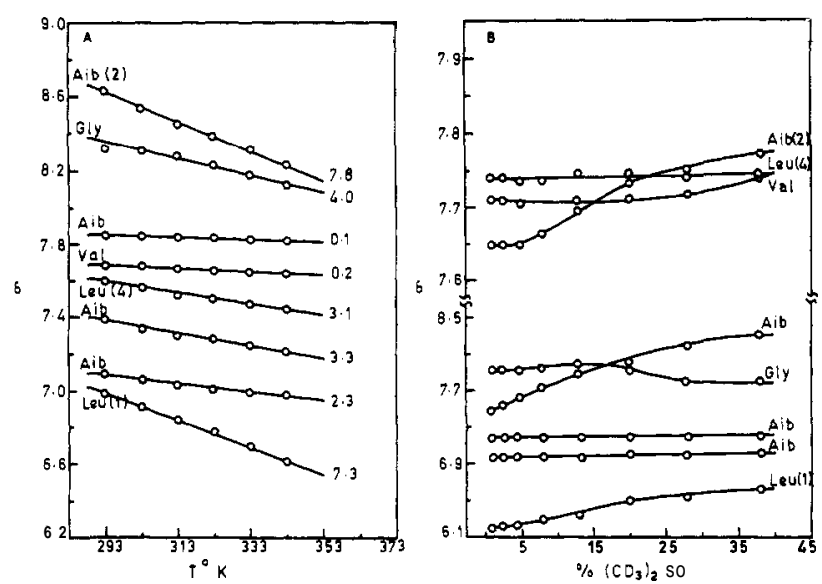

FIGURE 7: (A) Temperature dependence of NH chemical shifts in peptide 3 in $\left(\mathrm{CD}_{3}\right)_{2} \mathrm{SO}$. d $\delta / \mathrm{d} T$ values $\left(\times 10^{3} \mathrm{ppm} /{ }^{\circ} \mathrm{C}\right)$ are indicated. (B) Dependence of NH chemical shifts on solvent composition in $\mathbf{3}$.
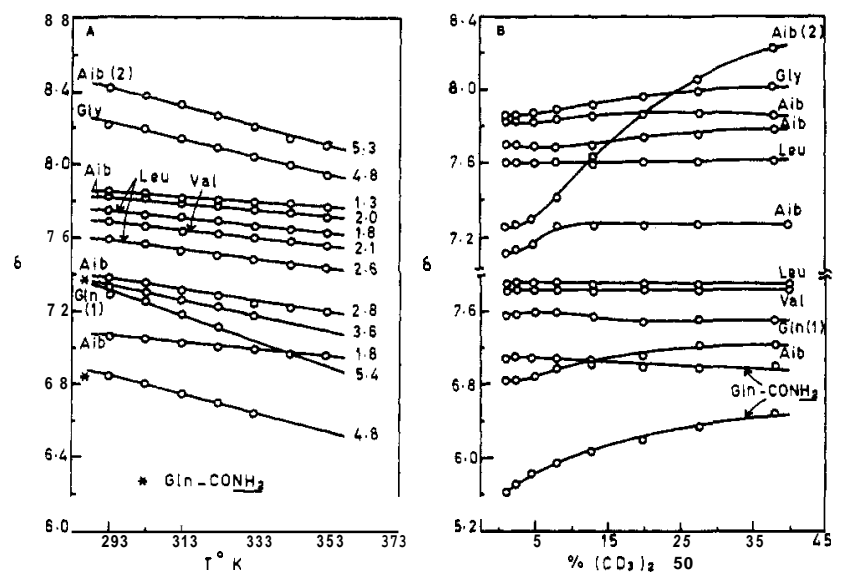

FIGURE 8: (A) Temperature dependence of NH chemical shifts in peptide 4 in $\left(\mathrm{CD}_{3}\right)_{2} \mathrm{SO}$. d $\delta / \mathrm{d} T$ values $\left(\times 10^{3} \mathrm{ppm} /{ }^{\circ} \mathrm{C}\right)$ are indicated. (B) Dependence of NH chemical shifts on solvent composition in 4.

In the undecapeptide 4, the $\mathrm{Gln}(1)$ and one Aib $\mathrm{NH}$ groups are clearly solvent exposed, as shown by their high $\mathrm{d} \delta / \mathrm{d} T$ values. It should be noted that as in the case of 2 , the $G \ln (1)$ $\mathrm{NH}$ shows an abnormally low-field resonance position in $\mathrm{CDCl}_{3}$. Seven $\mathrm{NH}$ groups yield very low $\mathrm{d} \delta / \mathrm{d} T$ values $(<3$ $\mathrm{X} 10^{-3} \mathrm{ppm} /{ }^{\circ} \mathrm{C}$ ) and also show very little sensitivity to solvent, suggesting their involvement in intramolecular hydrogen bonds. Only the Gly N H exhibits an intermediate $\mathrm{d} \delta / \mathrm{d} T$ value and shows a small solvent shift. A particularly noteworthy feature of the solvent titration curve (Figure 8) is the behavior of the Aib N H group, assigned to Aib(2). As in the case of the smaller peptides, a distinct transition is observed at $\left(\mathrm{CD}_{3}\right)_{2} \mathrm{SO}$ concentrations above $5 \%$.

\section{Discussion}

The stereochemical rigidity imposed on the peptide backbone by the presence of Aib residues permits the use of NMR techniques in establishing intramolecularly hydrogen-bonded structures in acyclic peptides. As noted in earlier studies (Nagaraj et al., 1979; Nagaraj \& Balaram, 1981 a; Venkatachalapathi \& Balaram, 1981; Iqbal \& Balaram, 1981), excellent correlations between conformations determined by different spectroscopic methods and X-ray studies are obtained in the case of Aib peptides. In particular, the problems of dynamic averaging, which vitiate many NMR studies of linear oligopeptides, are less significant in the case of Aibcontaining sequences. The results reported in the preceding section establish the following features for the suzukacillin fragments. (i) In the pentapeptide 1, the Leu(4) N H group is intramo- lecularly hydrogen bonded. (ii) The Leu(3), Leu(6), and one Aib NH group are strongly hydrogen bonded in 2 , while the Gly NH and an Aib NH also participate in hydrogen bonding in the heptapeptide. (iii) Five $\mathrm{NH}$ groups (Leu(4), Val(7), and three Aib NH groups) are involved in intramolecular hydrogen bonding in the nonapeptide 3. The NMR data do not strongly favor hydrogen-bond formation involving the Gly(3) NH. (iv) The undecapeptide 4 favors a solution conformation in which seven $\mathrm{NH}$ groups are strongly hydrogen bonded. Again, the Gly (5) NH appears to be involved in a weak interaction.

These observations support a structure for 1 , involving an Aib(2)-Gly (3) $\beta$ turn, with a $4 \rightarrow 1$ hydrogen bond between Leu(1) CO and Leu(4) NH. This conformation is compatible with the NMR results and also the known tendency of Aib-X sequences to adopt $\beta$-turn conformations (Nagaraj et al., 1979; Rao et al., 1980; Nagaraj \& Balaram, 1981a). The heptapeptide 2 appears to favor a $3_{10}$ helical conformation with consecutive type III $\beta$ turns having $G \ln (1)$ - $A i b(2), A i b(2)$ $\operatorname{Leu}(3)$, Leu(3)-Aib(4), Aib(4)-Gly(5), and Gly(5)-Leu(6) as the corner residues. Such a conformation would leave $G \ln (1)$ and $\mathrm{Aib}(2) \mathrm{NH}$ groups free and leads to the earlier assignment of $\mathrm{Aib}(2) \mathrm{NH}$. The Gly(5)-Leu(6) $\beta$ turn may be expected to be more flexible, suggesting that the Aib $\mathrm{N} \mathrm{H}$ with a relatively high $\mathrm{d} \delta / \mathrm{d} T$ value $\left(3.2 \times 10^{-3} \mathrm{ppm} /{ }^{\circ} \mathrm{C}\right)$ may correspond to $\mathrm{Aib}(7) \mathrm{NH}$.

In the 11-21 fragment 4, there are ten backbone $\mathrm{NH}$ groups. Of these, seven are involved in strong intramolecular hydrogen bonding, while Gly(5) NH appears to be less shielded from the environment. The exposed $\mathrm{NH}$ groups are $\mathrm{G} \ln (1)$ and Aib(2). The favored conformation for the undecapeptide must therefore be largely $3_{10}$ helical. The schematic hydrogen-bonding pattern is illustrated in Figure 9. The presence of Pro(8) interrupts a regular sequence of $3_{10}$ hydrogen bonds and leads to the possibility of an alternative $5-1$ hydrogen bond at the -Leu-Aib-Pro-Val-Aib- segment. This is illustrated in Figure 9. The only difference is in the nature of the car. bonyl groups involved in hydrogen bonding. The two structural possibilities cannot be distinguished exclusively on the basis of ${ }^{1} \mathrm{H}$ NMR evidence. An extensive analysis of IR data on alamethicin fragments has, in fact, suggested the possibility of a single $5 \rightarrow 1$ hydrogen bond in this segment (Rao et al., 1980). A similar possibility is also likely in this suzukacillin fragment, which differs from the corresponding alamethicin fragment only in the replacement of a Val residue by Leu. The 'H NMR results, however, clearly support a highly folded, largely $3_{10}$ helical conformation for the 11-21 fragment. Deletion of the Gln-Aib dipeptide in the 13-21 fragment 3 leads to a reduction in the number of intramolecular hydrogen bonds.

In all four peptides, the ${ }^{1} \mathrm{H}$ NMR parameters of the Gly $\mathrm{NH}$ do not unambiguously support its involvement in a hydrogen bond. With the exception of the heptapeptide 2, all other peptides yield rather high $\mathrm{d} \delta / \mathrm{d} T$ values for the Gly $\mathrm{NH}$. The solvent shifts are, however, low in every case. This may reflect primary structure effects on NMR parameters. The lack of a $\mathrm{C}^{\alpha}$ substituent may result in anomalous values for the Gly NH parameters in these peptides. Alternatively, a degree of flexibility may be present at the Leu-Gly-Aib segment in these molecules. The Aib NH group showing clearly discontinuous behavior in the solvent titration experiments in the longer peptides 2 and $\mathbf{4}$ may be assigned to the Aib(2) NH group. It is possible that in both these peptides the presence of $G \ln (1)$ may lead to the population of conformational states involving the side-chain carboxamide group with either the 

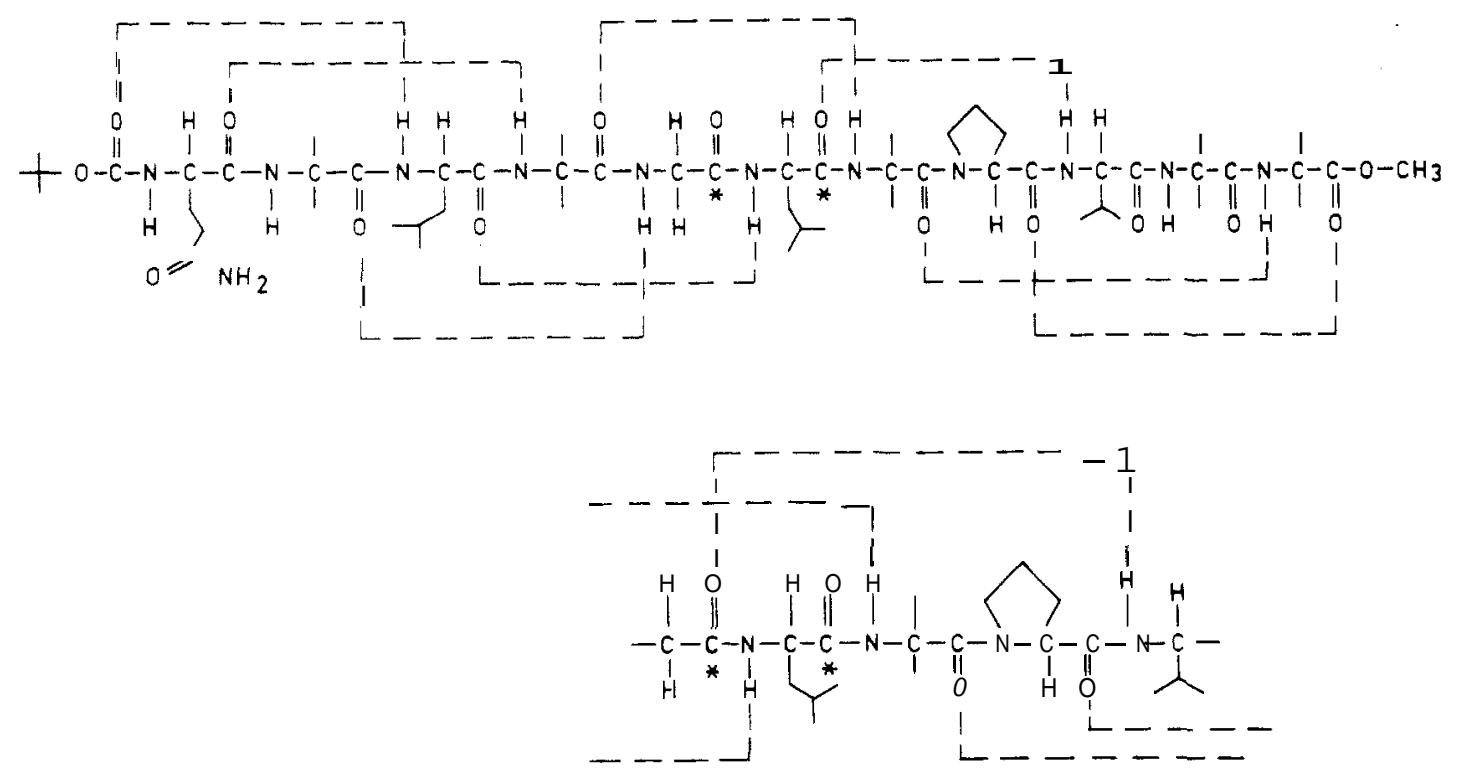

FIGURE 9: (Top) Schematichydrogen-bonding scheme in 4 showing eight $4-4$ hydrogen bonds. (Bottom) Alternative $5 \rightarrow 1$ hydrogen bonding possibility. The starred $\mathrm{CO}$ groups can be differentiated in the two schemes.

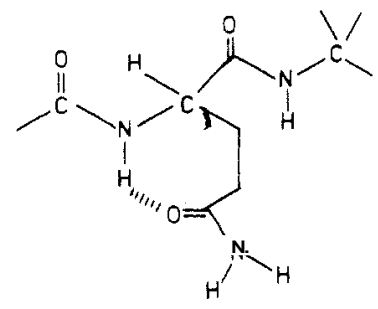

(a)

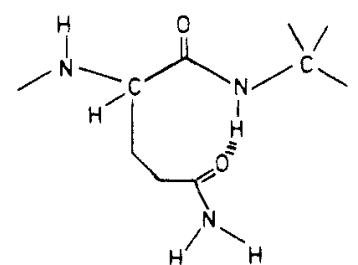

(b)
FIGURE 10: Possible hydrogen-bonded structures involving the Gln side-chain and backbone amide groups. (a) Gln NH to side-chain CO. (b) Side-chain CO to Aib (2) NH.

$\mathrm{G} \ln (1)$ or Aib(2) NH group (Figure 10). The breaking up of such structural features in the polar solvent $\left(\mathrm{CD}_{3}\right)_{2} \mathrm{SO}$ may account for the discontinuities in the solvent titration curves of $\mathrm{Aib}(2) \mathrm{NH}$. Furthermore, such conformations may account for the low-field position of $\mathrm{G} \ln (1) \mathrm{NH}$ in $\mathrm{CDCl}_{3}$. In the interpretation of the NMR data, we have ignored the possible effects of peptide aggregation on NMR parameters. This is a reasonably good assumption for the Aib peptides, at the concentration used, and has been borne out in earlier comparisons of IR, NMR, and X-ray results (Nagaraj et al., 1979; Rao et al., 1980; Nagaraj \& Balaram, 1981a). In specific model studies of Aib peptides, aggregation effects have been shown to be minimal in $\left(\mathrm{CD}_{3}\right)_{2} \mathrm{SO}$ solution (Venkatachalapathi \& Balaram, 1981). However, the possibility that rigid helical peptides aggregate through amino-terminal groups and Gln side-chain functions needs to be considered for these suzukacillin fragments. Further studies in this direction are currently under way.

The NMR studies outlined above strongly support a highly folded, largely $3_{10}$ helical conformation for the 11-21 segment of suzukacillin. The 1-10 segment has earlier been shown to favor a $3_{10}$ helical structure stabilized by eight intramolecular hydrogen bonds (Iqbal \& Balaram, 1981). It is therefore likely that the 1-21 hydrophobic segment of suzukacillin will prefer a rodlike helical conformation. Two assay systems involving liposomal cation transport (Nagaraj et al., 1980) and uncoupling of oxidative phosphorylation in rat liver mitochondria (Mathew et al., 1981) have been developed in this laboratory for examining the channel forming ability of Aib-containing polypeptides. Recent experiments suggest that the 1-21 suzukacillin fragment forms cation channels in liposomes and also uncouples oxidative phosphorylation (M. K. Mathew, unpublished results). These results imply that the hydrophobic 1-21 suzukacillin fragment can form transmembrane channel structures, which modify membrane properties. Further studies are under way on the modes of aggregation of peptide helices and the relationship between peptide structure and membrane-modifying activity.

\section{References}

Boheim, G., Janko, K., Liebfritz, D., Ooka, T., Konig, W. A., \& Jung, G. (1976) Biochim. Biophys. Actu 433,182-199. Iqbal, M., \& Balaram, P. (1981) J.Am. Chem. Soc. (in press). Jung, G., Konig, W. A., Liebfritz, D., Ooka, T., Janko, J., \& Boheim, G. (1976) Biochim. Biophys. Actu 433,164-181.

Kopple, K. D., Ohnishi, M., \& Go, A. (1969) J. Am. Chem. Soc. 91, 4264-4272.

Mathew, M. K., Nagaraj, R., \& Balaram, P. (1981) Biochem. Biophys. Res. Commun. 98, 548-555.

Nagaraj, R., \& Balaram, P. (1981a) Biochemistry 20, 2828. Nagaraj, R., \& Balaram, P. (1981b) Tetrahedron 37, $1263-1270$.

Nagaraj, R., Shamala, N., \& Balaram, P. (1979) J. Am. Chem. Soc. 101, 16-20.

Nagaraj, R., Mathew, M. K., \& Balaram, P. (1980) FEBS Lett. 121, 365-368.

Pitner, T. P., \& Urry, D. W. (1972) J.Am. Chem. Soc. 94, 1399-1400.

Prasad, B. V. V., Shamala, N., Nagaraj, R., Chandrasekaran, R. C., \& Balaram, P. (1979) Biopolymers 18, 1635-1646. Prasad, B. V. V., Shamala, N., Nagaraj, R., \& Balaram, P. (1980) Actu Crystallogr., Sect. B B36, 107-110.

Rao, Ch. P., Nagaraj, R., Rao, C. N. R., \& Balaram, P. (1979) FEBS Lett. 100, 244-248. 
Rao, Ch. P., Nagaraj, R., Rao, C. N. R., \& Balaram, P. (1980) Biochemistry 19, 425-431.

Shamala, N., Nagaraj, R., \& Balaram, P. (1978) J. Chem. Soc., Chem. Commun. 996-997.
Venkatachalapathi, Y. V., \& Balaram, P. (1981) Biopolymers $20,625-628$.

Venkatachalapathi, Y. V., Nair, C. M. K., Vijayan, M., \& Balaram, P. (1981) Biopolymers 20, 1123-1136. 